\title{
VARIAÇÕES GENÉTICAS PARA CARACTERÍSTICAS DO SISTEMA RADICULAR DE MUDAS DE BARU (Dipteryx alata Vog.) ${ }^{1}$
}

\author{
Adelson Nascimento Oliveira ${ }^{2}$, Ana Carolina da Silva², Sebastião Carlos da Silva Rosado ${ }^{2}$ e Érica \\ Alvarenga Crespo Rodrigues ${ }^{2}$
}

\begin{abstract}
RESUMO - Este estudo objetivou estimar os parâmetros genéticos relativos à qualidade do sistema radicular de mudas de baru. Para isso, foram utilizadas mudas provenientes de sementes colhidas em 21 árvores-matriz de polinização livre no Município de Capinópolis, Minas Gerais. Quarenta e cinco dias após a germinação, as imagens das raízes de 20 mudas de cada progênie foram obtidas por "scanner" ótico. Na análise de variância, houve variação significativa entre as progênies quanto aos caracteres: comprimento total de raízes, volume de raízes, diâmetro médio e número de raízes finas. As análises indicaram altos valores de herdabilidade e coeficiente de variação genética, indicando que altos ganhos genéticos poderão ser obtidos mediante a seleção de matrizes.
\end{abstract}

Palavras-chave: Seleção de progênies, "scanner" ótico e ganhos genéticos.

\section{GENETIC VARIATIONS FOR ROOT SYSTEM TRAITS OF BARU SEEDLINGS (Dipteryx alata Vog.)}

\begin{abstract}
Baru seedlings originated from seeds collected from 21 open-pollinated progenies were used in Capinópolis, Minas Gerais, Brazil, in order to estimate genetic parameters concerning the quality of their root system. Forty-five days after germination, the root images of twenty seedlings of each progeny were obtained using an optical scanner. The analysis of variance showed significant variation among progenies in total root length, root volume, average diameter and the number of fine roots. The analysis showed high heritability and genetic variation, indicating that high genetics gains are possible to be obtained by means of mother-tree selections.
\end{abstract}

Keywords: Progenies selection, optical scanner and genetic gain.

\section{INTRODUÇÃO}

A qualidade do sistema radicular das plantas está diretamente relacionada com a sua capacidade de absorver nutrientes e água do solo e, assim, estabelecer seu crescimento e desenvolvimento. Plantas mais eficientes na absorção são mais adaptadas ao ambiente, possuem maior capacidade de estabelecimento no campo e, conseqüentemente, maior ganho em produção. $\mathrm{O}$ comprimento radicular é uma das melhores variáveis para se estimar a capacidade de absorção de água e nutrientes (BOHM, 1979), juntamente com a quantidade de raízes finas, que permite maximizar o fenômeno da absorção (MELLO, 1997). A maior parte do cálcio, por exemplo, é absorvida pelas raízes finas, responsáveis também pela maior absorção de água (RUSSEL, 1981). Além disso, as raízes finas são estruturas radiculares, onde ocorrem as colonizações por fungos micorrízicos e, a partir do crescimento micelial, a melhoria no processo de transferência de nutrientes e água para a planta

\footnotetext{
${ }^{1}$ Recebido em 18.03.2005 e aceito para publicação em 13.09.2006.

${ }^{2}$ Departamento de Ciências Florestais da Universidade Federal de Lavras, Cx.P. 37, 37200-000 Lavras-MG, Brasil. E-mail: <adelsonoliveira@ig.com.br>, <carol.sil@zipmail.com.br>, <scrosado@ufla.br>, e <eacrespo@ uflanet.com.br>.
} 
hospedeira, aumentando, principalmente, a absorção de fósforo (SANNI Jr., 1976).

A distribuição das raízes no solo, sua quantidade e profundidade, além de depender de fatores ambientais, como tipo de solo, grau de compactação e de interações entre o ambiente e a planta (FANTE Jr., 1997), depende do genótipo da planta (MELLO, 1997). Dessa forma, a distribuição do sistema radicular e o conhecimento da variação genética dos caracteres que expressam a sua qualidade são fundamentais para a escolha do material genético capaz de propiciar maior crescimento e desenvolvimento da planta.

O baru (Dipteryx alata Vog.) pertencente à família Fabaceae, é uma espécie típica do Cerrado, que apresenta grande potencial econômico, pois pode ser utilizado para diversos fins: alimentício, forrageiro, oléico, madeireiro e paisagístico, podendo, também, ser empregado em recuperação de áreas degradadas e plantio de enriquecimento de pastagens. Estudos como os de Oliveira (1998) e Rocha et al. (2002) têm mostrado variabilidade genética nos caracteres de crescimento (diâmetro e altura), indicando que essa espécie tem potencialidade para o melhoramento genético. Para obter árvores de baru com crescimento mais rápido, pode-se adotar a estratégia de seleção de genótipos com maior comprimento radicular e maior quantidade de raízes, principalmente finas.

Durante muito tempo, os estudos sobre o crescimento radicular foram realizados somente através de métodos que avaliavam os caracteres, como: massa seca e comprimento de raiz, bem como área e volume de solo explorados por elas (BOHM, 1979). Esses métodos genéticos, além de demandar muito tempo, não permitem um conhecimento adequado quanto à quantidade de raízes finas e diâmetro das raízes, que são importantes variáveis para a determinação de sua qualidade. Atualmente, com o uso de computadores e softwares específicos para análises de imagens, que podem ser obtidas por máquinas fotográficas digitais ou "scanner" ótico, as medições no sistema radicular têm sido aperfeiçoadas, envolvendo maior quantidade de caracteres avaliados, exatidão dos dados obtidos e redução do tempo na obtenção desses dados (COSTA et al., 2001; 2002). Estudos dessa natureza foram realizados por Costa et al. $(2000 ; 2001 ; 2002)$ em Zea mays, Hordeum vulgare, Avena sativa, Glycine max, Triticum aestivum e Fragaria x ananassa e, também, em espécies arbóreas como a Gleditsia triacanthos, Celtis occidentalis, Acer saccharinum, Acer platanoide e Fraxinus pennsylvanica. Esses métodos possibilitaram a condução de estudos do sistema radicular de diferentes genótipos, permitindo a seleção daquelas com maior crescimento e desenvolvimento.

Assim, os objetivos deste trabalho foram: i) avaliar os componentes de variância (fenotípica e genotípica) e herdabilidade em famílias de meios-irmãos de mudas de baru para os caracteres radiculares e ii) avaliar a possibilidade de selecionar progênies com maior eficiência do sistema radicular na captura de nutrientes de água.

\section{MATERIAL E MÉTODOS}

Foram coletadas sementes de 21 árvores-matriz de polinizações livres de baru (Dipteryx alata Vog.), distanciadas entre si em pelo menos $100 \mathrm{~m}$. Essas árvores encontram-se no Município de Capinópolis, em Minas Gerais, localizada a $18^{\circ} 41^{\prime}$ de latitude sul e 49³4' de longitude oeste do Meridiano de Greenwich, com altitude de $620 \mathrm{~m}$. A temperatura mínima é de $17,7^{\circ} \mathrm{C}$, a máxima de $30,1^{\circ} \mathrm{C}$ e a precipitação anual média de $1.530,2 \mathrm{~mm}$. As sementes foram semeadas em copos plásticos de $500 \mathrm{ml}$ com substrato constituído por areia esterilizada em estufa à temperatura de $200^{\circ} \mathrm{C}$ por um período de $2 \mathrm{~h}$. As mudas permaneceram em casa de vegetação com a temperatura mantida constante de $30^{\circ} \mathrm{C}$ e umidade de $80 \%$. O experimento foi conduzido em ensaio de blocos ao acaso com quatro repetições, 21 progênies e cinco plantas por parcela.

Quarenta e cinco dias após a germinação das sementes, as mudas foram colhidas e, no sistema radicular de cada uma, foram feitas três leituras com o "scanner" ótico HP ScanJet 3c/T (Hewlett-Packard), com resolução 1.600 dpi. Dessas leituras, foi estimada uma média por muda, utilizada na análise. A avaliação das imagens foi realizada usando-se o programa WinRhizo, versão 2003a (RÉGEN..., 2001). Com esse programa, foram avaliados o comprimento total da raiz $(\mathrm{cm})$, o volume de raízes $\left(\mathrm{cm}^{3}\right)$, o diâmetro médio das raízes $(\mathrm{mm})$ e do número de raízes finas, considerando-se, como raízes finas, aquelas com diâmetro menor que 0,5 mm. Esses dados foram submetidos à análise de variância, seguindose o procedimento de blocos casualizados com informação dentro de parcela, usando-se o programa GENES - Genética Quantitativa e Estatística Experimental V.5 (CRUZ, 2001). 
O modelo biométrico utilizado foi: $\mathrm{Y}_{\mathrm{ijk}}=\mathrm{m}+\mathrm{g}_{\mathrm{i}}$ $+\beta_{\mathrm{j}}+\varepsilon_{\mathrm{ij}}+\delta_{\mathrm{ijk}}$, em que: $\mathrm{Y}_{\mathrm{ijk}}$ : valor observado na k-ésima planta, no i-ésimo genótipo, do j-ésimo bloco; $\mu$ : média geral observada; $\mathrm{g}_{\mathrm{i}}$ : efeito do i-ésimo genótipo (efeito aleatório); $\beta_{\mathrm{j}}$ : efeito do j-ésimo bloco (efeito aleatório); $\varepsilon_{\mathrm{ij}}$ : erro da parcela $\mathrm{ij}$; e $\delta_{\mathrm{ijk}}$ : erro da planta k, do i-ésimo genótipo, no j-ésimo bloco (Quadro 1).

Para as estimativas dos componentes de variância (Quadro 1), dos valores de herdabilidade e dos coeficientes de correlação fenotípica de Pearson entre famílias de meios-irmãos foram utilizadas as expressões descritas por Cruz (2001).

\section{RESULTADOS E DISCUSSÃO}

Houve variações altamente significativas entre as progênies quanto ao comprimento total de raízes, volume de raízes, diâmetro e número de raízes finas (Quadro 2). Isso indica a possibilidade da seleção nessas variáveis no programa de melhoramento. Essas variações nas características do sistema radicular podem ter relação com a capacidade de crescimento e desenvolvimento das progênies dessa espécie. Um sistema radicular mais desenvolvido, com maiores quantidades, principalmente de raízes finas, pode resultar em uma muda mais vigorosa e com mais chances de sobrevivência em ambientes com escassez de nutrientes e água. Rodrigues et al. (2003), estudando clones de Eucalyptus sp. através da visualização de raízes por "scanner" ótico, também encontram variações significativas entre os clones, quanto aos caracteres do sistema radicular, como comprimento total, diâmetro médio e número de raízes finas.

A variância genética, a herdabilidade e o coeficiente de variação genético mostraram-se maior dentro do que entre famílias. Há, portanto, maiores chances de ganhos genéticos quando se seleciona, além das famílias de maior desempenho, também as melhores plantas dentro de cada família. Os valores de herdabilidade, em geral, mostraram-se altos, na maioria em torno de 100\% (Quadro 3). Os coeficientes de variação genético foram superiores para os caracteres CT e RF, em torno de $35 \%$ dentro de famílias e $20 \%$ entre famílias. Somente para o diâmetro não houve alto valor de coeficiente de variação genético entre famílias $(6,89 \%)$. Os valores da relação $\mathrm{CV}_{\mathrm{g}} / \mathrm{CV}_{\mathrm{e}} \mathrm{e}$ $\mathrm{CV}_{\mathrm{gd}} / \mathrm{CV}_{\mathrm{e}}$ foram superiores à unidade, tanto entre quanto dentro de famílias. Destaca-se que a relação $\mathrm{CV}_{\mathrm{g}} / \mathrm{CV}_{\mathrm{e}}$ dentro de famílias chegaram a valores maiores que 2. Vencovsky e Barriga (1992) concluíram que essa relação, quando atinge valor igual ou superior à unidade, indica que é possível obter ganhos genéticos representativos no melhoramento.

Quadro 1 - Estrutura da análise de variância das estimativas dos parâmetros fenotípicos, genotípicos e ambientais

Table 1 - Structure of the variance analysis for the estimation of phenotypic, genotypic and environmental parameters

\begin{tabular}{lccc}
\hline Fonte de variação & QM & $\mathrm{E}(\mathrm{QM})$ & $\mathrm{F}$ \\
\hline Blocos & $\mathrm{QMB}$ & $\sigma_{\mathrm{d}}^{2}+\mathrm{n} \sigma_{\mathrm{e}}^{2}+\mathrm{ng} \sigma_{\mathrm{b}}^{2}$ & - \\
Progênies (P) & $\mathrm{QMP}$ & $\sigma_{\mathrm{d}}^{2}+\mathrm{n} \sigma_{\mathrm{e}}^{2}+\mathrm{nr} \sigma_{\mathrm{g}}^{2}$ & $\mathrm{QMP} / \mathrm{QME}$ \\
Erro entre parcelas & $\mathrm{QME}$ & $\sigma_{\mathrm{d}}^{2}+\mathrm{n} \sigma_{\mathrm{e}}^{2}$ & $\mathrm{QME} / \mathrm{QMD}$ \\
Erro dentro de parcelas & $\mathrm{QMD}$ & $\sigma_{\mathrm{d}}^{2}$ & - \\
\hline
\end{tabular}

$\sigma_{\mathrm{b}}^{2}$ : variância entre blocos; $\sigma_{\mathrm{g}}^{2}$ : variância genotípica; $\sigma_{\mathrm{e}}^{2}$ : variância entre parcelas; $\sigma_{\mathrm{d}}^{2}$ : variância dentro de parcelas; e $\mathbf{n}, \mathbf{g}$ e $\mathbf{r}$ referemse, respectivamente, ao número de plantas por parcela, número de genótipos ou famílias e número de blocos.

Quadro 2 - Resumo das análises de variância dos caracteres da raiz, como comprimento total (CT), volume (VR), diâmetro médio (DM) e número de raízes finas (RF), em progênies de polinização livre de Dipteryx alata, aos 45 dias após a germinação

Table 2 - Variance analyses summary for root system traits such as total length (CT), volume (VR), average diameter (DM) and number of fine roots $(R F)$, in open-pollinated progenies of Dipteryx alata

\begin{tabular}{|c|c|c|c|c|c|}
\hline \multirow[t]{2}{*}{ Fonte de variação } & \multirow[t]{2}{*}{ GL } & \multicolumn{4}{|c|}{ Quadrados médios } \\
\hline & & $\mathrm{CT}$ & VR & $\mathrm{DM}$ & RF \\
\hline Blocos & 3 & 34645,99 & 1,2521 & 0,1353 & 92884,3 \\
\hline Progênies (P) & 20 & $35122,05^{* *}$ & $1,3699^{* *}$ & $0,1230^{* *}$ & $40527,8^{* *}$ \\
\hline Erro entre parcela & 60 & 5615,47 & 0,2162 & 0,0258 & 9959,5 \\
\hline Erro dentro de parcela & 332 & 3330,31 & 0,1392 & 0,0149 & 6354,3 \\
\hline Média & - & $189,3(\mathrm{~cm})$ & $1,45\left(\mathrm{~cm}^{3}\right)$ & $1,02(\mathrm{~mm})$ & 189,55 \\
\hline
\end{tabular}

** Significativo, pelo teste $\mathrm{F}(\mathrm{p}<0,01)$. 
Quadro 3 - Estimativas dos parâmetros fenotípicos, genotípicos e ambientais nos caracteres das raízes como comprimento total (CT), volume (VR), diâmetro médio (DM) e número de raízes finas (RF), em progênies de polinização livre de Dipteryx alata, aos 45 dias após a germinação

Table 3 -Estimates of phenotypic, genotypic and environmental parameters for root traits such as total length (CT), volume $(V R)$, average diameter $(D M)$ and the number of fine roots $(R F)$, in open-pollinated progenies of Dipteryx alata, 45 days after germination

\begin{tabular}{|c|c|c|c|c|}
\hline Parâmetros genéticos & $\mathrm{CT}$ & VR & DM & $\mathrm{RF}$ \\
\hline Var. genética entre famílias & 1492,89 & 0,0584 & 0,0049 & 1546,61 \\
\hline Var. genética dentro de famílias & 4478,68 & 0,1751 & 0,0148 & 4639,82 \\
\hline Var. fenotípica dentro de famílias & 3330,31 & 0,1392 & 0,0149 & 6354,33 \\
\hline Var. residual & 462,47 & 0,0156 & 0,0022 & 729,62 \\
\hline Var. total & 5565,45 & 0,2231 & 0,0231 & 9429,72 \\
\hline $\mathrm{h}^{2}$ (US = média famílias) & $84,01 \%$ & $84,22 \%$ & $79,05 \%$ & $75,43 \%$ \\
\hline $\mathrm{h}^{2}$ (US = dentro famílias $)$ & $100,00 \%$ & $100,00 \%$ & $98,87 \%$ & $73,02 \%$ \\
\hline $\mathrm{CV}_{\mathrm{e}}$ & $11,36 \%$ & $8,58 \%$ & $4,60 \%$ & $14,25 \%$ \\
\hline $\mathrm{CV}_{\mathrm{g}}^{\mathrm{e}}$ entre famílias & $20,41 \%$ & $16,61 \%$ & $6,89 \%$ & $20,75 \%$ \\
\hline $\mathrm{CV}_{\mathrm{gd}}^{\mathrm{g}}$ dentro de famílias & $35,35 \%$ & $28,77 \%$ & $11,94 \%$ & $35,94 \%$ \\
\hline $\mathrm{CV}_{\mathrm{g}} / \mathrm{CV}_{\mathrm{e}}$ & 1,80 & 1,94 & 1,50 & 1,46 \\
\hline $\mathrm{CV}_{\mathrm{gd}}^{\mathrm{g}} / \mathrm{CV}_{\mathrm{e}}$ & 3,11 & 3,35 & 2,59 & 2,52 \\
\hline
\end{tabular}

Var.: variância; $\mathrm{H}^{2}$ : herdabilidade; US: unidade de seleção; $\mathrm{CV}_{\mathrm{e}}$ : coeficiente de variação experimental; e $\mathrm{CV}_{\mathrm{g}}$ : coeficiente de variação genético.

É possível observar que as progênies de números $1,18,21$ e 22 apresentaram os maiores valores de CT e que todas elas, exceto a de número 22, também exibiram as maiores quantidades de raízes finas (Quadro 4). Tanto CT quanto RF apresentaram altos valores de herdabilidade, indicando que podem ser usados na seleção. As progênies 1,18 e 21 apresentaram altos valores de CT e RF e baixos valores de DM, o que são características desejáveis, pois raízes mais finas possuem maior absorção de nutrientes e água. As progênies com os maiores valores de VR foram $1,6,9,14,18$ e 22 .

As correlações fenotípicas entre CT, VR e RF foram altas, positivas e significativamente diferentes de zero $(\mathrm{p}<0,01)$, indicando que a seleção praticada com base em qualquer um desses caracteres influenciará positivamente os outros dois. Isso é vantajoso, pois há a possibilidade de se obterem ganhos expressivos em uma característica de difícil medição (ex. número de raízes finas), mediante a seleção de uma característica de mais fácil medição (ex. comprimento total).

Entre CT e DM, a correlação foi negativa e significativamente diferente de zero $(\mathrm{p}<0,01)$. Raízes de maior comprimento apresentaram também menor diâmetro e vice-versa. É uma correlação negativa bastante benéfica, pois tanto o comprimento radicular maior quanto o diâmetro menor são desejáveis no sistema radicular. Outra correlação negativa significativamente diferente de zero a $1 \%$ foi encontrada entre DM e RF. Esperava-se essa correlação negativa, pois, quanto mais raízes finas, menor o diâmetro médio do sistema radicular. Não houve correlação significativamente diferente de zero entre VR e DM.

Quadro 4-Valores médios de comprimento total (CT), volume (VR), diâmetro médio (DM) e número de raízes finas (RF), em progênies de Dipteryx alata, aos 45 dias após a germinação

Table 4-Average values of total length (CT), volume (VR), diameter (DM) and number of fine roots $(R F)$ in root systems of Dipteryx alata progenies 45 days after germination

\begin{tabular}{ccccc}
\hline Progênies & \multicolumn{4}{c}{ Caracteres } \\
\cline { 2 - 5 } & $\mathrm{CT}(\mathrm{cm})$ & $\mathrm{VR}\left(\mathrm{cm}^{3}\right)$ & $\mathrm{DM}(\mathrm{mm})$ & $\mathrm{RF}$ \\
\hline 1 & 252,42 & 1,95 & 1,00 & 271,75 \\
3 & 135,33 & 0,93 & 0,95 & 155,00 \\
4 & 163,13 & 1,16 & 0,98 & 169,00 \\
5 & 179,41 & 1,30 & 0,99 & 194,50 \\
6 & 188,67 & 1,66 & 1,07 & 217,00 \\
7 & 150,00 & 1,35 & 1,11 & 124,00 \\
8 & 148,86 & 1,41 & 1,11 & 161,75 \\
9 & 201,29 & 1,69 & 1,05 & 202,00 \\
10 & 140,69 & 1,38 & 1,18 & 149,25 \\
11 & 208,76 & 1,51 & 0,97 & 218,75 \\
12 & 124,85 & 1,23 & 1,17 & 104,00 \\
14 & 216,50 & 1,78 & 1,05 & 215,00 \\
16 & 146,54 & 1,22 & 1,08 & 142,50 \\
17 & 192,04 & 1,28 & 0,93 & 181,50 \\
18 & 274,86 & 1,94 & 0,97 & 277,50 \\
20 & 202,18 & 1,44 & 0,98 & 177,25 \\
21 & 239,95 & 1,50 & 0,91 & 256,25 \\
22 & 259,64 & 1,77 & 0,94 & 208,25 \\
23 & 193,40 & 1,39 & 0,96 & 217,25 \\
24 & 180,32 & 1,45 & 1,04 & 176,50 \\
25 & 184,66 & 1,23 & 0,94 & 175,50 \\
\hline & & & &
\end{tabular}


Quadro 5 - Estimativas dos coeficientes de correlação de Pearson entre os caracteres do sistema radicular de baru aos 45 dias após a germinação comprimento total (CT), volume (VR), diâmetro médio (DM) e número de raízes finas (RF)

Table 5 - Pearson's correlation coefficients between root system traits - total length (CT), volume (VR), average diameter $(D M)$ and the number of fine roots $(R F)$ in baru seedlings 45 days after germination

\begin{tabular}{lcccc}
\hline Variáveis & $\mathrm{V}_{(\mathrm{X})}$ & $\mathrm{V}_{(\mathrm{Y})}$ & $\operatorname{Cov}_{(\mathrm{X}, \mathrm{Y})}$ & $\hat{\mathrm{r}}$ (correlação) \\
\hline CT x VR & 1779,50 & 0,0692 & 9,0904 & $0,82^{* *}$ \\
CT x DM & 1779,50 & 0,0062 & $-1,9695$ & $-0,59^{* *}$ \\
CT x RF & 1779,50 & 2045,40 & 1722,41 & $0,90^{* *}$ \\
VR x DM & 0,0692 & 0,0062 & $-0,0011$ & $-0,05^{\mathrm{NS}}$ \\
VR x RF & 0,0692 & 2045,40 & 8,9368 & $0,75^{* *}$ \\
DM x RF & 0,0062 & 2045,40 & $-2,0627$ & $-0,58^{* *}$ \\
\hline
\end{tabular}

NS. Não significativo pelo teste $\mathrm{t}(\mathrm{p}>0,05), \mathrm{e}^{* *}$ significativo, pelo teste $\mathrm{t}(\mathrm{p}<0,01)$.

\section{CONCLUSÕES}

A herdabilidade indica a possibilidade de seleção pelas características das raízes de mudas de baru, especificamente quanto ao comprimento total, volume, diâmetro e número de raízes finas.

Há correlações positivas entre comprimento total, volume e número de raízes finas, indicando que, se a seleção for praticada para qualquer um dos caracteres citados, influenciará positivamente os demais.

\section{REFERÊNCIAS BIBLIOGRÁFICAS}

BOHM, W. Methods of studying root systems. New York: Springer-Verlag, 1979. 188 p.

COSTA, C. et al. Sampling method for measurement of large root systems with scanner-based image analysis. Agronomy Journal, v. 92, n. 4, p. 621-627, 2000.

COSTA, C. et al. Root contrast enhancement for measurement with optical scanner-based image analysis. Canadian Journal of Botany, v. 79, n. 1, p. $23-29,2001$.

COSTA, C. et al. Root morphology of contrasting maize genotypes. Agronomy Journal, v. 94, n. 1, p. 96-101, 2002.

CRUZ, C. D. Programa Genes: Versão Windows. Viçosa, MG: Universidade Federal de Viçosa, 2001. 648 p.

FANTE Jr., L. Sistema radicular de aveia forrageira avaliado por diferentes métodos, incluindo processamento de imagens digitais. 1997. 119 f. Tese (Doutorado em Energia Nuclear na Agricultura) - Centro de Energia Nuclear na Agricultura, Piracicaba, 1997.
MELlo, S. L. M. Características do sistema radicular de povoamentos de eucaliptos propagados por sementes e estacas. 1997. 79 f. Dissertação (Mestrado em Ciência Florestal) - Escola Superior de Agricultura Luiz de Queiroz, Piracicaba, 1997.

OLIVEIRA, A. N. Variação genética entre e dentro de procedências de baru (Dipteryx alata) Vog.). 1998. 80 f. Dissertação (Mestrado em Engenharia Florestal) Universidade Federal de Lavras, Lavras, 1998.

REGENT INSTRUMENTS INC. Programa WinRhizo versão 2002a. Quebéc: 2001.

ROCHA, M.G.B.; ROCHA, D.; CLEMENTE, V.M. Teste de procedências e progênies de baru (Dipteryx alata Vogel). In: ROCHA, M.G.B. Melhoramento de espécies arbóreas nativas. Belo Horizonte: DDFS/Instituto Estadual de Florestas, 2002. p. 29-40.

RODRIGUES, E. A. C. et al. Qualidade morfológica de mudas de Eucalyptus avaliada em imagens obtidas por scanner óptico. In: CONGRESSO FLORESTAL BRASILEIRO, 8., 2003, São Paulo. Anais... São Paulo: Monferrer Produções, 2003.

RUSSEL, R. S. Plant Root Systems - their function and interaction with the soil. In: SYMPOSIUM ON THE SOIL/ROOT SYSTEM, 1981, Londrina.

Proceedings... Londrina: Instituto Agronômico do Paraná-IAPAR, 1981.p. 3-20.

SANNI Jr., R. L. Vesicular-arbuscular mycorrhiza in some Nigerian soils: the effect of Gigaspora gigantea on the growth of rice. The New Phytologist, v. 7, n. 3, p. 763-774, 1976.

VENCOVSKY, R.; BARRIGA, P. Genética biométrica no fitomelhoramento. Riberão Preto: 1992. 496 p.

R. Árvore, Viçosa-MG, v.30, n.6, p.905-909, 2006 